\title{
Webcam
}

MILLER, Daniel; SINANAN, Jolynna.

Londres: Polity Press, 2014. 220p.

\section{Webcam no contexto da antropologia digital}

Por Monica Machado ${ }^{1}$

O livro Webcam é a mais recente publicação do núcleo de pesquisa Material Culture (cultura material) do Departamento de Antropologia Cultural da University College London. E se situa no contexto de consolidação do campo analítico da antropologia digital. Essa abordagem vem ganhando destaque internacional, a partir especialmente das publicações Tales from Facebook (MILLER, 2011), Migration and New Media: transnational Families and Polymedia (MANDIANOU; MILLER, 2011 e com destaque para Digital Anthropology organizado por Horst; Miller (2012).

Segundo Miller \& Sinanan (2014), uma das chaves conceituais para o debate sobre as conexões entre humanos, cultura e tecnologia é o tema da autenticidade: discursos que avaliam o quanto o ser humano se torna mais ou menos mediado com o suporte tecnológico. E existe a tendência da defesa de associação entre tecnologia e declínio sociocultural. Muitas teses compreendem o mundo digital como um ambiente superficial e responsável pela perda da essencialidade humana. Para os autores de Webcam, Platão, em Phaedus, já havia produzido a mesma crítica em relação à escrita: um suporte que se fixava fora da mente só poderia destruir a essência qualitativa da memória e da criatividade em nome de uma relação artificial com as sensibilidades do mundo. A noção, afirmam os antropólogos, está fundada no lamento do passado autêntico, expressando-se como leitmotif do mundo moderno.

\footnotetext{
${ }^{1}$ Universidade Federal do Rio de Janeiro - UFRJ, Rio de Janeiro, RJ, Brasil.

E-mail:monica@insider.com.br
} 
A antropologia digital compreende que a história vem nos ensinando que um meio vai retendo traços culturais de outro e há lugar para todos na cultura contemporânea. Os autores partem do pressuposto de que a interaçao face a face e a comunicação digital são igualmente culturais. Toda a produção material tecnológica da internet é analisada tendo como base o conceito de cultura material, compreendido como campo de análise das relações sociais entre sujeitos e bens. Um pressuposto que dialoga com a visão de Bourdieu (1990) sobre o habitus: a correlação entre a formação de ideias e as condições de produção, os vínculos entre sujeitos sociais e campos simbólicos onde as lutas se travam em contextos de conflito. Dialogam também com Goffman, 2004 com a ideia de representação teatral e na noção de que atores sociais não estão presos as estruturas e negociam seus papéis nas interações.

Pensando, portanto, sobre o conceito de campo simbólico, Miller e Sinanan, 2014 encontram em Van Dijcks (2013) uma voz ativa que reflete sobre as marcações da memória no mundo digital. Para a autora, longe de ser um instrumento de desmaterialização, o mundo digital reelabora o sentido de memória, adiciona mais capacidade para estocar a memória fora da mente, em um sistema multimodal e coletivo. Miller e Sinanan, 2014 afirmam que não nos tornamos mais mediatizados em função da cultura digital. Assim precisamos responder ao questionamento: então o impacto das novas tecnologias é insignificante? E sugerem que a sensibilidade cultural é afetada com a nova tecnologia. Os autores desenvolvem a theory of attainment, noção que pode ser traduzida como novas marcações de sentido, novos valores que são dispostos pela cultura. E afirmam sua relevância para lidar com o dilema: o quanto a tecnologia muda a humanidade e, ao mesmo tempo, trabalha com a rejeição da ideia de que seu suporte nos faz mais ou menos humanos ou mediados, e por isso não domestica a nossa mente. Mas a natureza da mediação é alterada. O desafio está em estudar o impacto da nova tecnologia e as mudanças nos modos de consciência e outros modos de vida, sem ver esse processo como um aumento ou declínio da nossa essencialidade humana. Essa perspectiva rejeita, por 
exemplo, a noção de que estamos nos transformando em pós-humanos ou cyborgs.

Quais são, então, as marcas de attainment do contexto da webcam? A primeira noção trabalhada no livro é o conceito de autoconsciência. Todas as pessoas que usam a webcam falam com o outro, mas ao mesmo tempo podem se ver na tela em um pequeno box no canto, durante todo o período da conversação. Assim, o texto revela a urgência de se repensar sobre a consciência de si na alta modernidade. No passado tínhamos o lago, os espelhos, fotografias e vídeos com recortes de poses. No Skype, com horas de conversação, vemos além do outro, a nós mesmos como uma rotina de observação do self. O mito grego do Narciso inspirou a criação do conceito de eu como objeto e investimento: uma noção entre o autoerotismo e o amor objetal na teoria psicanalítica freudiana. A fase do espelho foi concebida por Lacan como o ponto central para formação do primeiro esboço do ego da criança, na imagem de gestalt do próprio corpo e de sua autoimagem.

Para a antropologia, para além da interpretação psicanalítica, também é na vivência cultural e na interação que a construção do sujeito se estrutura. Essa nova experiência de se ver em modo contínuo na webcam faz repensar os conceitos sobre a imaginação do self. Miller argumenta que comparando os princípios ontológicos do ser entre ingleses e moradores de Trinidad observamos profundas diferenças nas reflexões sobre a subjetividade. Os ingleses, informantes da pesquisa, têm uma crença absoluta em que o eu interior é profundo e subjetivo, enquanto a aparência é superficial. Já nas etnografias na cultura de Trinidad nota-se que o eu interior guarda segredos, mas se a essencialidade da pessoa começa no interior, fundamentalmente se revela na superfície e é possível julgar o outro por sua aparência. E por isso estão investidos em criar um estilo ou visual revelador da alma. Por isso, frente a webcam, seus informantes na Inglaterra vivenciam uma lógica de estranhamento com a sua autoimagem: não se reconhecem, estranham a voz, o formato dos olhos, os relances de perfil. Há o conflito entre a imagem idealizada do self e a representação em tempo real promovida pela câmera. Já em Trinidad, 
os entrevistados acreditam que a aparência online é reveladora da personalidade por isso se expõem de modo mais visceral: gesticulando muito, marcando as expressões faciais. Assim buscam revelar a subjetividade pela objetividade da tela.

A noção de intimidade é outra marca de "attainment", revista no contexto da webcam, traduzindo-se no conceito de "always-on", uma nova imaginação sobre o viver e as regras de sociabilidade. Os autores refletem sobre a ampliação do sentido de co-presença nas relações sexuais mediadas ou na experiência emocional das relações de parentesco. A princípio a webcam pode transmitir a impressão de uma cena fabricada, uma versão fake da intimidade, mas a construção da ambivalência de sentimentos permite aos indivíduos a vivência de um senso de pertencimento. O tema da imigração e das relações transacionais de parentesco se consolidou como uma tradição nos estudos antropológicos, hoje se estuda as relações mediadas pela tecnologia como um dos conceitos centrais para avaliar o potencial das novas mídias como forma de reconectar pessoas do mesmo núcleo familiar que vivem separadas.

O senso de co-presença também faz repensar o sentido de lugar e a ideia de casa. O advento da webcam problematiza a noção de lugar tangível, físico mas também de lugar afetivo e sentido de familiaridade. Miller e Sinanan, 2014 argumentam que as relações de parentesco entre pais e crianças sempre envolverão graus de tensão e sentidos ideais de como as relações deveriam ser. Os autores identificam como a webcam acentua as contradições, mas em certa medida, resolve alguns problemas como o da autonomia dos filhos e da supervisão dos pais.

A fundamental contribuição antropológica do estudo da webcam nos faz refletir como o desenvolvimento tecnológico cresceu exponencialmente e influenciou as dinâmicas interativas na vida cotidiana. E também observar como as culturas são altamente criativas e principalmente diacrônicas nos usos das mídias sociais. Trata-se, portanto, de uma obra instigante que, com o rigor científico proposto por Miller e Sinanan, 2014, salienta as diferentes cosmologias dos grupos sociais e as motivações socioculturais para a interação digital. 
150 WEBCAM NO CONTEXTO DA ANTROPOLOGIA DIGITAL

\section{Referências}

BORDIEU, P. O poder simbólico. Rio de Janeiro: Bertrand Brasil, 1990.

GOFFMAN, E. A representação do eu na vida cotidiana. 12. ed. Rio de Janeiro: Vozes, 2004.

HORST, H.; MILLER, D. Digital Anthropology. Londres: Berg, 2012.

LIVINGSTONE, S. Children and internet. Cambridge: Polity Press, 2009.

MANDIANOU. M; MILLER, D. Migration and New Media: transnational families and polymedia. Londres: Routledge, 2011.

MILLER, D. Consumption and its consequences. Cambridge: Polity Press, 2012.

Stuff. Cambridge: Polity Press, 2010.

Tales from Facebook. Cambridge: Polity Press, 2011.

MILLER, Daniel; SINANAN, Jolynna. Webcam London: Polity Press, 2014. 220p.

VAN DIJCK, J. The culture of connectivity. Oxford: Oxford University Press, 2013.

Data de submissão: 12/12/2014

Data de aceite: 22/06/2015 